Article

\title{
Analysis of Floral Volatile Components and Antioxidant Activity of Different Varieties of Chrysanthemum morifolium
}

\author{
Lu Yang ${ }^{1,2}$, Aobulikasimu Nuerbiye ${ }^{3}$, Ping Cheng ${ }^{1,2}$, Jin-Hui Wang ${ }^{3}$ and Hong Li ${ }^{1, *}$ \\ 1 Xinjiang Academy of Forestry, Urumqi 830000, China; yanglukitty127@163.com (L.Y.); \\ chengping1985@163.com (P.C.) \\ 2 Economic forest product quality inspection and testing center of the State Forestry Administration (Urumqi), \\ Urumqi 830052, China \\ 3 Xinjiang Medical University, Urumqi 830000,China; xjlky_2@163.com (A.N.); tcm_shz@aliyun.com (J.-H.W.) \\ * Correspondence: xjlky_sys@163.com; Tel.: +188-9916-1201
}

Received: 6 September 2017; Accepted: 17 October 2017; Published: 23 October 2017

\begin{abstract}
This study investigated the volatile flavor compounds and antioxidant properties of the essential oil of chrysanthemums that was extracted from the fresh flowers of 10 taxa of Chrysanthemum morifolium from three species; namely Dendranthema morifolium (Ramat.) Yellow, Dendranthema morifolium (Ramat.) Red, Dendranthema morifolium (Ramat.) Pink, Dendranthema morifolium (Ramat.) White, Pericallis hybrid Blue, Pericallis hybrid Pink, Pericallis hybrid Purple, Bellis perennis Pink, Bellis perennis Yellow, and Bellis perennis White. The antioxidant capacity of the essential oil was assayed by spectrophotometric analysis. The volatile flavor compounds from the fresh flowers were collected using dynamic headspace collection, analyzed using auto thermal desorber-gas chromatography/mass spectrometry, and identified with quantification using the external standard method. The antioxidant activities of Chrysanthemum morifolium were evaluated by DPPH and FRAP assays, and the results showed that the antioxidant activity of each sample was not the same. The different varieties of fresh Chrysanthemum morifolium flowers were distinguished and classified by fingerprint similarity evaluation, principle component analysis (PCA), and cluster analysis. The results showed that the floral volatile component profiles were significantly different among the different Chrysanthemum morifolium varieties. A total of 36 volatile flavor compounds were identified with eight functional groups: hydrocarbons, terpenoids, aromatic compounds, alcohols, ketones, ethers, aldehydes, and esters. Moreover, the variability among Chrysanthemum morifolium in basis to the data, and the first three principal components (PC1, PC2, and PC3) accounted for $96.509 \%$ of the total variance $(55.802 \%, 30.599 \%$, and $10.108 \%$, respectively). PCA indicated that there were marked differences among Chrysanthemum morifolium varieties. The cluster analysis confirmed the results of the PCA analysis. In conclusion, the results of this study provide a basis for breeding Chrysanthemum cultivars with desirable floral scents, and they further support the view that some plants are promising sources of natural antioxidants.
\end{abstract}

Keywords: Chrysanthemum morifolium; ATD-GC/MS; antioxidant activity; principle component analysis (PCA); cluster analysis

\section{Introduction}

Chrysanthemum (Chrysanthemum morifolium Ramat.) belongs to the Asteraceae family of leading ornamental species, second only to the rose in terms of its market value [1]. Dendranthema morifolium (Ramat.) and Pericallis hybrida, called Qiuju and Fuguiju in China, are widely used in South China, either as a fragrant floral tea or as an anti-inflammatory herb in Traditional Chinese Medicine. They have 
been reported to possess antibacterial, antifungal, antispirochetal, anti-inflammatory, and antioxidant activities [2]. The flavonoids, alkaloids, and sesquiterpene lactones are thought to contribute to the pharmacological activities of Chrysanthemum morifolium [2-4]. A recent report indicated that the flavonoids in the extracts of Chrysanthemum morifolium protected the brain, liver, and kidney against lead-induced oxidative damage in mice. Moreover, the extracts provided significant protection against cerebral ischemia and reperfusion injury in rats through their antioxidant effect $[5,6]$.

Chrysanthemum species have also been proposed as a potential ingredient for herbal cosmetics for their tyrosinase inhibitory activity, which has been associated with antioxidant activation, whitening, and moisturizing effects [7-9].

Bellis perennis L. (Asteraceae), called Nvwangju, is an herbaceous perennial plant known as a traditional wound herb. It has been used for the treatment of bruises, broken bones, wounds, headaches, the common cold, stomach aches, eye diseases, eczema, skin boils, gastritis, diarrhea, bleeding, rheumatism, inflammation, and infections of the upper respiratory tract in traditional medicine [10].

Automatic thermal desorption (ATD) is a valuable method for the fractionation of plant volatile components that can be carried out online with gas chromatography (GC) analysis. Thermal desorption can present some advantages since it substantially simplifies analyses (there is no need for a concentration step after sampling) and it increases sensitivity (a large part of the pre-concentrated material may be recovered for determination), and detection limits and background noise are lower because of the disappearance of solvent components [11-13]. The use of coupled GC-MS affords additional qualitative information, which is of special interest for plant species whose composition has not been previously studied. Some examples of the application of ATD coupled to GC-MS for the identification and characterization of volatile components of plants of different families are given [14]. ATD-GC/MS is a fast, simple, and convenient method to analyze volatile compounds in flowers [15]. ATD-GC/MS has also been successfully applied to detection of pesticide residues [16]. Therefore, we investigated the feasibility of ATD-GC/MS as a tool to predict the aromatic components present in Chrysanthemum morifolium.

Recently, plants were studied on numerical taxonomic classification using multivariate data based on their morphological, biochemical, and molecular characteristics $[17,18]$. In particular, on the basis of the chemical components, like the volatile compounds in plants, multivariate analyses, such as principal component analysis (PCA) and cluster analysis, have been performed [19,20].

PCA used in the present study is essentially that described by Cooley and Lohnes in which a correlation matrix with unit values in its principal diagonal is used as input and the variable-vectors are standardized. Each vector, thus, has zero mean and unit variance and can be taken as being of unit length [21]. The selection of the optimum number of reference axes is necessary to explain the relationships between any particular set of variables. Different workers [22,23] have taken different approaches. Kaiser has suggested that the number of the axes should be restricted to the number of eigenvalues, which are greater than unity and the one used in the present study [24].

Cluster analysis is a type of multivariate analysis that divides data with close similarities into groups (clusters) that are meaningful and useful. If meaningful groups are the goal, then the clusters should capture the natural structure of the data. Therefore, as a technique for grouping clusters of similar traits based on the diverse characteristics of certain entities or subjects, cluster analysis can be utilized in situations where there are no clear or known classification criteria [17]. However, little research has been performed on the Chrysanthemum species, including the classification of species based on volatile compounds.

Antioxidants have been intensively studied in pharmaceutical and dermatological fields to prevent or treat disorders related to oxidative stress. In the past, antioxidants have also been used in the food industry to protect against the deterioration of food and in the cosmetic industry to delay or prevent skin aging. Free radicals and reactive oxygen species (ROS) are reported to be associated with several 
diseases, including inflammation [23] and aging and age-related diseases [25]. Importantly, free radical damage on the skin caused by ROS and UV-irradiation stress plays a key role in photoaging [26,27].

The present study was conducted to obtain clear inter-species classification by using multivariate analysis methods, such as PCA and cluster analysis, as well as by analyzing and comparing the volatile compounds of 10 taxa of three Chrysanthemum species. Moreover, the antioxidant activities of the three species were evaluated by DPPH and FRAP assay.

\section{Results}

\subsection{Optimization of ATD Parameters}

The duration of desorption is an important parameter and its optimization can improve desorption efficiency and sensitivity. Therefore, three desorption times are selected for testing: 15, 30, and $45 \mathrm{~min}$. As shown in Figure 1, a duration of desorption of $30 \mathrm{~min}, 18$ compounds were detected and the content of hydrocarbons, aromatics, esters were relatively high. While for $45 \mathrm{~min}, 15$ compounds were detected and the content of all compounds were low except the content of terpenoids. This phenomenon can be explained by the low volatility in addition to their thermal sensibility [28]. Therefore, a 30-min duration was confirmed as the optimization time condition. Tenax-TA and Tenax-GR are polymeric materials (styrene polyvinylbenzene) that are commonly used as an adsorbent for volatile compounds, especially for use with high temperatures. As can be seen in Figure 1, there is no distinctive difference, so the entire experiment path used Tenax-TA as an adsorbent for volatile compounds and the sampling time of $30 \mathrm{~min}$.

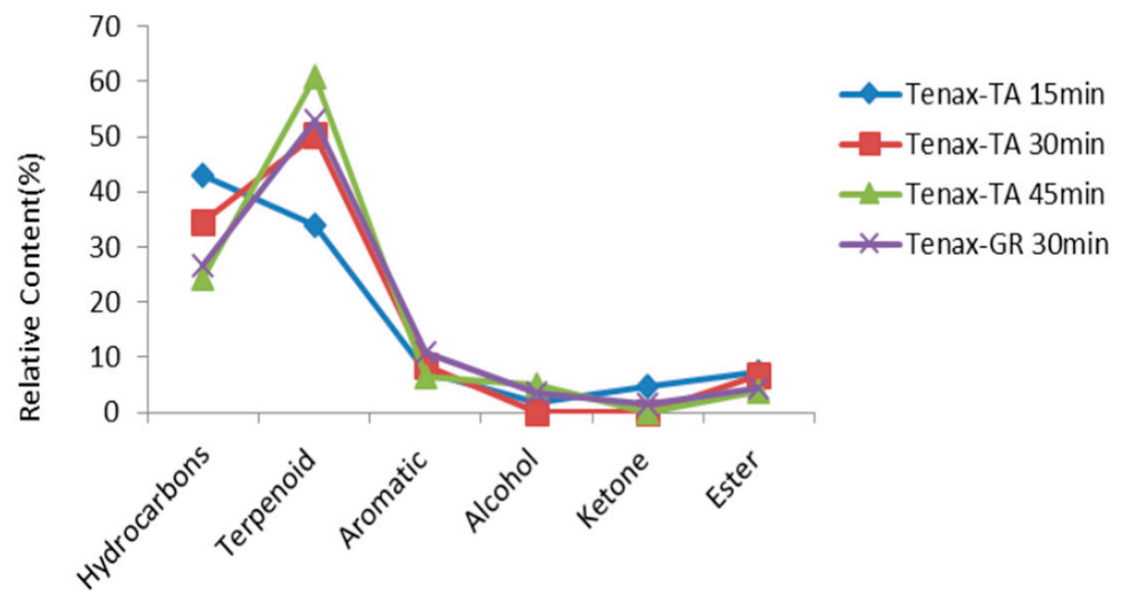

Figure 1. Percentage of alcohols, hydrocarbons, and other compounds released from Dendranthema morifolium (Ramat.) Yellow (No.1) in dependence of sampling times and absorbents.

\subsection{Comparison of Antioxidant Activities}

Two common in vitro assays were used to evaluate the antioxidant activities, and the results showed that the three species had significantly different antioxidant activity depending on the assay used (Table 1). In the DPPH assay, all of the extracts showed good radical scavenging activity. Samples of Dendranthema morifolium had a lower mean EC50 than that of Bellis perennis and a higher mean EC50 than that of Pericallis hybrida, but no significant difference was found $(p>0.05)$. In the FRAP assay, the antioxidant activity of Bellis perennis was significantly stronger than that of Dendranthema morifolium and Pericallis hybrida $(p<0.05)$ (Table 1). The results indicated that essential oil extracted from Chrysanthemum morifolium exhibited DPPH free radical scavenging activity, and therefore it could be applied as an antioxidant agent. 
Table 1. Antioxidant activity values for Chrysanthemum morifolium.

\begin{tabular}{cccccc}
\hline Samples & $\mathbf{1}$ & $\mathbf{2}$ & $\mathbf{3}$ & $\mathbf{4}$ & $\mathbf{5}$ \\
\hline DPPH IC50 $\left(\mathrm{mgml}^{-1}\right)$ & $0.089 \pm 0.003$ & $0.109 \pm 0.001$ & $0.091 \pm 0.008^{* *}$ & $0.097 \pm 0.007$ & $0.113 \pm 0.011$ \\
FRAP C $\left(\mathrm{Fe}^{2+}\right)\left(\mathrm{mmolg}^{-1}\right)^{3}$ & $2.300 \pm 0.011^{*}$ & $2.810 \pm 0.012 *$ & $2.110 \pm 0.021^{*}$ & $2.560 \pm 0.019 *$ & $3.170 \pm 0.017 *$ \\
\hline Samples & $\mathbf{6}$ & $\mathbf{7}$ & $\mathbf{8}$ & $\mathbf{9}$ & $\mathbf{1 0}$ \\
\hline DPPH IC50 $\left(\mathrm{mgml}^{-1}\right)$ & $0.108 \pm 0.009$ & $0.119 \pm 0.0010$ & $0.072 \pm 0.003$ & $0.080 \pm 0.005$ & $0.082 \pm 0.001$ \\
FRAP C $\left(\mathrm{Fe}^{2+}\right)\left(\mathrm{mmolg}^{-1}\right)^{3}$ & $3.090 \pm 0.022^{* *}$ & $3.209 \pm 0.019 *$ & $1.870 \pm 0.009 *$ & $1.990 \pm 0.010 *$ & $1.807 \pm 0.007 *$ \\
\hline
\end{tabular}

Note: Values for Chrysanthemum morifolium, which differ and were statistically significantly, are marked with "*”.

Analysis of variance was performed between various groups of Chrysanthemum morifolium. ${ }^{*} p<0.05$. ${ }^{* *} p<0.01$.

Antioxidant activity expressed as $\mathrm{mmol} \mathrm{FeSO}_{4}$ equivalents per $1 \mathrm{~g}$ sample.

\subsection{Analysis of Volatile Components and Release Quantity in Different Varieties of Chrysanthemum}

The presence, yield, and composition of secondary metabolites, such as volatile oils in plants, can be affected by several factors, including physiological variations, environmental conditions, geographic variations, genetic factors, and evolution [29].

A typical GC-MS total ion chromatogram (TIC) of the volatile chemical profile of Chrysanthemum is shown in Figure 2.

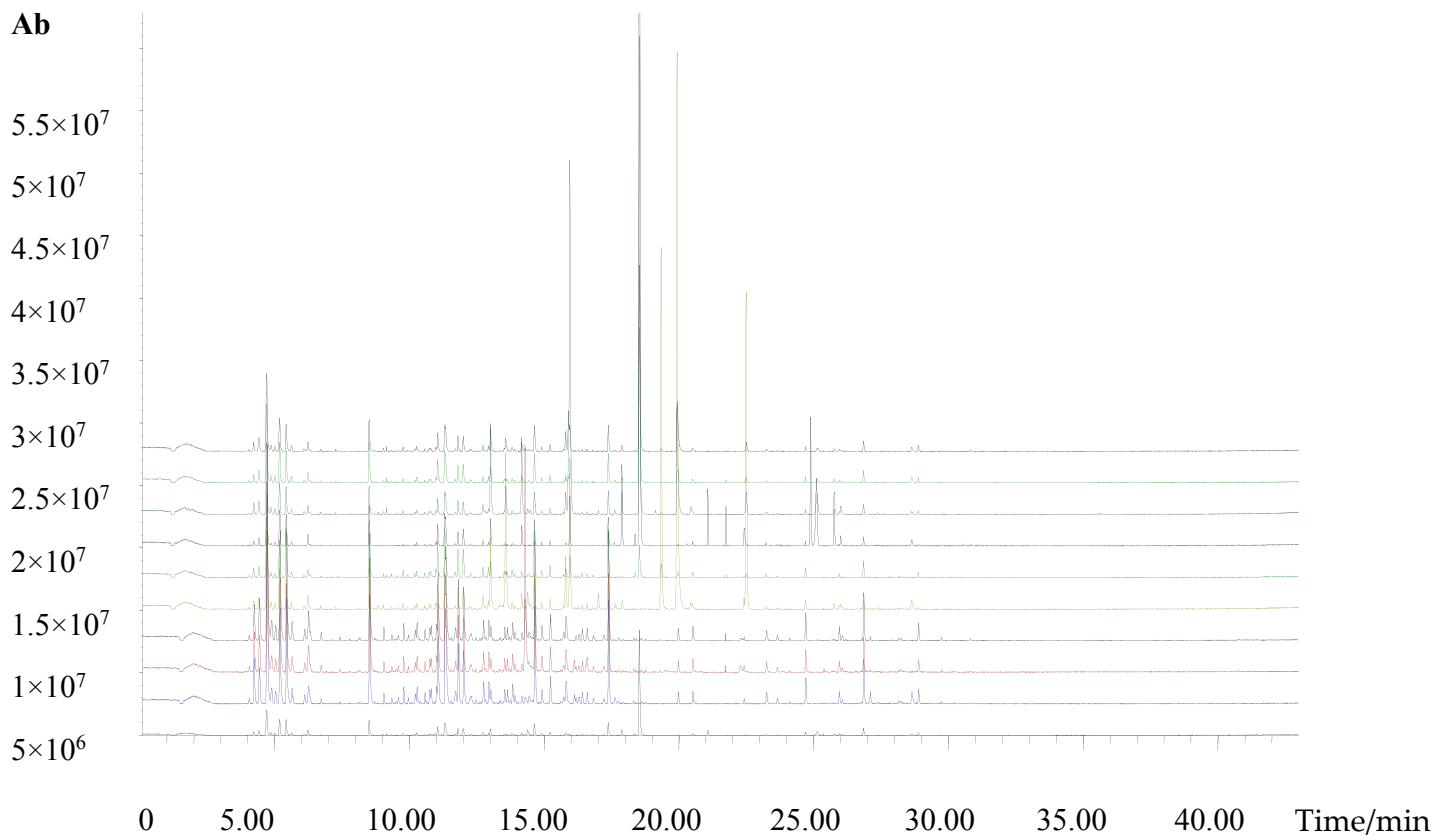

Figure 2. Typical total ion chromatogram of the volatile compounds in Chrysanthemum morifolium flowers. From top to bottom, Dendranthema morifolium (Ramat.) Yellow (No.1), Pericallis hybrida Blue (No.5), Pericallis hybrida Pink (No.6), Pericallis hybrida Purple (No.7), Dendranthema morifolium (Ramat.) Red (No.2), Dendranthema morifolium (Ramat.) Pink (No.3), Dendranthema morifolium (Ramat.) White (No.4), Bellis perennis White (No.10), Bellis perennis Pink (No.8), and Bellis perennis Yellow (No.9), respectively.

The volatiles of the 10 taxa are listed in Table 2. GC-MS analysis detected 36 compounds in the floral scent of Chrysanthemum, which were identified by their mass spectra and RI. Based on the classification of aromatic compounds of Chrysanthemum, volatile compounds were categorized as: terpenoid compounds, hydrocarbons, aromatic compounds, alcohols compounds, and flavor compounds. Hydrocarbons and terpenoids predominated, while the other compounds were typically present in smaller amounts. The 36 detected compounds included 10 hydrocarbons, 10 terpenoids, 4 aromatics, 4 alcohols, 3 ketones, 3 esters, 1 aldehydes, and 1 ether (Table 2). 
Camphor, $n$-hexane, ethyl acetate, 1,3,5-cycloheptatriene, ethyl benzene, o-xylene, eucalyptol, nonane, alpha-Pinene, and pentadecane were the most common components, and camphor, n-hexane, o-xylene, and eucalyptol were present at particularly high levels.

The volatile compound contents varied markedly among the 10 taxas. In Nos. $\mathbf{1 , 4}, \mathbf{6 , 8} \mathbf{8}$, and 10, camphor $(4.19 \mu \mathrm{g}, 1.29 \mu \mathrm{g}, 9.53 \mu \mathrm{g}, 2.70 \mu \mathrm{g}, 3.76 \mu \mathrm{g}$, and $4.06 \mu \mathrm{g})$ was the highest component. In No.2, endo-Borneol $(6.01 \mu \mathrm{g})$ was the most abundant, and it was only detected in this cultivar. In No.6, the content of the volatile compound benzaldehyde $(2.67 \mu \mathrm{g})$ was the highest component. Even though camphor was found to be the main volatile compound in the three species, the other volatile compounds were reported differently according to the taxa. There were seven same compounds in the ten taxa. As shown in Figure 3, the floral volatile components were significantly different among Chrysanthemum samples. The amount of terpenoids (51\%) was the highest in No.1. No.2 contained $32 \%$ alcohols, $17 \%$ ketones, and 15\% terpenoids. No.3 contained 53\% hydrocarbons and $15 \%$ terpenoids. No. 4 contained $70 \%$ terpenoids, $10 \%$ hydrocarbons, and $9 \%$ aromatics. No. 5 contained $56 \%$ hydrocarbons, $15 \%$ terpenoids, and $11 \%$ esters. No.6 contained $49 \%$ hydrocarbons, $18 \%$ aldehydes, and $12 \%$ terpenoids. No.7 contained 59\% hydrocarbons, $11 \%$ terpenoids, and $10 \%$ aromatics. No.8 contained $45 \%$ terpenoids, $33 \%$ hydrocarbons, and $7 \%$ aromatics. No. 9 contained $54 \%$ terpenoids, $16 \%$ hydrocarbons, and $14 \%$ alcohols. No.10 contained $43 \%$ terpenoids, $10 \%$ hydrocarbons, and $27 \%$ ether compounds. From superficial observation of the structures, Nos. 5, 6, and 7 were similar, and Nos. 8, 9, and 10 were similar. This also showed that the content from a species of Chrysanthemum morifolium was similar. 
Table 2. Volatile compounds released from the flowers of 10 varieties of Chrysanthemum morifolium.

\begin{tabular}{|c|c|c|c|c|c|c|c|c|c|c|c|c|c|c|c|}
\hline \multirow{2}{*}{ NO. } & \multirow{2}{*}{$\begin{array}{l}\text { Retention } \\
\text { Time (min) }\end{array}$} & \multirow{2}{*}{ Compounds } & \multirow{2}{*}{$\begin{array}{l}\text { Molecular } \\
\text { Formula }\end{array}$} & \multirow{2}{*}{$\begin{array}{c}\text { Relative } \\
\text { Molecular Mass }\end{array}$} & \multicolumn{10}{|c|}{ Content ( $\mu \mathrm{g})$} & \multirow{2}{*}{ MS Fragment Peaks } \\
\hline & & & & & 1 & 2 & 3 & 4 & 5 & 6 & 7 & 8 & 9 & 10 & \\
\hline 1 & 4.217 & Ethanol & $\mathrm{C}_{2} \mathrm{HH}_{5} \mathrm{O}$ & 46.0 & nd & nd & 0.369 & nd & 0.567 & 0.463 & 0.467 & nd & nd & nd & $31,46,60$ \\
\hline 2 & 4.412 & Acetone & $\mathrm{C}_{3} \mathrm{H}_{6} \mathrm{O}$ & 58.0 & 0.222 & nd & 0.472 & nd & 0.574 & 0.502 & 0.653 & nd & 0.141 & 0.133 & $31,38,41,58$ \\
\hline 3 & 4.699 & Methylene chloride & $\mathrm{CH}_{2} \mathrm{C}_{12}$ & 84.0 & 1.13 & 0.731 & 2.88 & 0.861 & 2.772 & 2.348 & 2.854 & 0.904 & 0.751 & 0.677 & $35,49,84,88$ \\
\hline 4 & 4.856 & Pentane, 2-methyl- & $\mathrm{C}_{6} \mathrm{H}_{14}$ & 86.1 & nd & nd & 0.459 & nd & 0.190 & 0.195 & 0.266 & nd & nd & nd & $41,56,71,86$ \\
\hline 5 & 5.175 & $\mathrm{n}$-Hexane & $\mathrm{C}_{6} \mathrm{H}_{14}$ & 86.1 & 0.705 & 0.421 & 2.19 & 0.433 & 1.53 & 1.35 & 1.72 & 0.557 & 0.357 & 0.309 & $29,41,43,57,60,86$ \\
\hline 6 & 5.424 & Ethyl Acetate & $\mathrm{C}_{4} \mathrm{H}_{8} \mathrm{O}_{2}$ & 88.1 & 0.664 & 0.291 & 1.54 & 0.347 & 1.56 & 1.15 & 1.53 & 0.509 & 0.310 & 0.252 & $29,43,61,70,88$ \\
\hline 7 & 5.63 & Cyclohexane & $\mathrm{C}_{6} \mathrm{H}_{12}$ & 84.1 & nd & nd & 0.263 & nd & 0.234 & 0.220 & 0.284 & nd & nd & nd & $41,56,60,69,84$ \\
\hline 8 & 6.236 & Benzene & $\mathrm{C}_{6} \mathrm{H}_{6}$ & 78.0 & 0.173 & nd & 0.342 & nd & 0.252 & 0.263 & 0.277 & nd & nd & nd & $31,39,41,43,50,52,56,78$ \\
\hline 9 & 8.498 & 1,3,5-Cycloheptatriene & $\mathrm{C}_{7} \mathrm{H}_{8}$ & 92.1 & 0.615 & 0.397 & 0.754 & 0.443 & 1.58 & 1.41 & 1.45 & 0.586 & 0.299 & 0.239 & $39,51,65,91$ \\
\hline 10 & 11.037 & Ethylbenzene & $\mathrm{C}_{8} \mathrm{H}_{10}$ & 107 & 0.275 & 0.163 & 0.254 & 0.197 & 0.644 & 0.591 & 0.592 & 0.283 & 0.136 & nd & $39,51,65,77,91,106$ \\
\hline 11 & 11.795 & Nonane & $\mathrm{C}_{9} \mathrm{H}_{20}$ & 128 & 0.231 & 0.172 & 0.262 & nd & 0.703 & 0.634 & 0.731 & 0.234 & 0.118 & nd & $41,57,71,85,99,128$ \\
\hline 12 & 11.995 & o-Xylene & $\mathrm{C}_{8} \mathrm{H}_{10}$ & 106 & 0.282 & 0.191 & 0.227 & 0.173 & 0.765 & 0.670 & 0.741 & 0.275 & 0.132 & nd & $39,51,65,75,91,103,109$ \\
\hline 13 & 12.753 & Linalye Acetate & $\mathrm{C}_{12} \mathrm{H}_{20} \mathrm{O}_{2}$ & 196 & nd & nd & nd & nd & 0.202 & nd & nd & nd & nd & nd & $39,43,57,71,113$ \\
\hline 14 & 13.002 & alpha.-Pinene & $\mathrm{C}_{10} \mathrm{H}_{16}$ & 136 & 0.213 & 0.577 & 0.109 & 0.253 & 0.198 & 0.159 & 0.153 & 0.199 & 0.631 & 0.715 & $41,79,93,98,121,136$ \\
\hline 15 & 13.57 & Camphene & $\mathrm{C}_{10} \mathrm{H}_{16}$ & 136 & nd & 1.439 & nd & nd & nd & nd & nd & nd & 0.437 & 0.207 & $29,43,57,70,98$ \\
\hline 16 & 13.828 & 1-Decene & $\mathrm{C}_{10} \mathrm{H}_{20}$ & 140 & nd & nd & nd & nd & 0.204 & 0.190 & nd & nd & nd & nd & $29,41,57,71,83,112,125$ \\
\hline 17 & 14.29 & Benzaldehyde & $\mathrm{C}_{7} \mathrm{H}_{6} \mathrm{O}$ & 106 & nd & nd & nd & 0.180 & nd & 2.67 & 0.629 & nd & 0.199 & 0.612 & $51,77,106$ \\
\hline 18 & 14.382 & beta.-Pinene & $\mathrm{C}_{10} \mathrm{H}_{16}$ & 136 & 0.193 & nd & nd & nd & nd & nd & nd & nd & nd & nd & $41,69,79,93,121,136$ \\
\hline 19 & 14.636 & Decane & $\mathrm{C}_{10} \mathrm{H}_{22}$ & 142 & 0.407 & 0.293 & 0.511 & 0.243 & 1.20 & 1.02 & 1.20 & 0.415 & 0.215 & 0.186 & $43,57,71,85,99,113,142$ \\
\hline 20 & 15.232 & Decane, 4-methyl- & $\mathrm{C}_{11} \mathrm{H}_{24}$ & 156 & nd & nd & nd & nd & 0.305 & 0.288 & 0.307 & nd & nd & nd & $53,57,71,84,113$ \\
\hline 21 & 15.789 & D-Limonene & $\mathrm{C}_{10} \mathrm{H}_{16}$ & 136 & nd & 0.432 & nd & nd & 0.326 & 0.269 & 0.336 & nd & 0.377 & 0.159 & $\begin{array}{c}41,53,68,79,93,107,121, \\
136\end{array}$ \\
\hline 22 & 15.946 & Eucalyptol & $\mathrm{C}_{10} \mathrm{H}_{18} \mathrm{O}$ & 154 & nd & 1.177 & 0.868 & 0.477 & nd & nd & nd & 0.312 & 0.295 & 3.60 & $65,79,93,121,136$ \\
\hline 23 & 17.37 & Undecane & $\mathrm{C}_{11} \mathrm{H}_{24}$ & 156 & 0.449 & 0.307 & 0.539 & 0.262 & 1.26 & 1.11 & 1.33 & 0.428 & 0.228 & 0.193 & $43,57,71,85,98,112,127,156$ \\
\hline 24 & 17.879 & cis-Ocimene & $\mathrm{C}_{10} \mathrm{H}_{16}$ & 136 & 0.214 & nd & nd & 0.832 & nd & nd & nd & nd & 0.148 & 0.177 & $27,41,53,67,79,93,105,121,136$ \\
\hline 25 & 18.528 & $\begin{array}{c}\text { Camphor } \\
\text { Bicyclo[3.1.1] }\end{array}$ & $\mathrm{C}_{10} \mathrm{H}_{14} \mathrm{O}$ & 150 & 4.19 & nd & 1.29 & 9.53 & nd & nd & nd & 2.70 & 3.76 & 4.06 & $39,65,79,91,107,122,150$ \\
\hline 26 & 19.34 & $\begin{array}{l}\text { hept-2-en-6-one, } \\
\text { 2,7,7-trimethyl- }\end{array}$ & $\mathrm{C}_{10} \mathrm{H}_{16} \mathrm{O}$ & 152 & nd & 3.08 & 0.350 & nd & nd & nd & nd & nd & nd & nd & $41,55,69,81,95,108,152$ \\
\hline 27 & 19.93 & endo-Borneol & $\mathrm{C}_{10} \mathrm{H}_{18} \mathrm{O}$ & 154 & nd & 6.01 & nd & nd & nd & nd & nd & 0.347 & 1.52 & 1.23 & $41,55,67,95,110,139$ \\
\hline 28 & 21.072 & verbenol & $\mathrm{C}_{10} \mathrm{H}_{16} \mathrm{O}$ & 152 & 0.204 & nd & nd & 0.481 & nd & nd & nd & nd & nd & nd & $43,81,91,109,119,134$ \\
\hline 29 & 21.742 & Carveol & $\mathrm{C}_{10} \mathrm{H}_{16} \mathrm{O}$ & 152 & nd & nd & nd & 0.309 & $\mathrm{Nd}$ & nd & $\mathrm{Nd}$ & nd & $\mathrm{Nd}$ & $\mathrm{nd}$ & $43,79,91,107,119,134$ \\
\hline 30 & 22.398 & Carvone & $\mathrm{C}_{10} \mathrm{H}_{14} \mathrm{O}$ & 150 & nd & nd & nd & 0.229 & $\mathrm{Nd}$ & nd & $\mathrm{Nd}$ & nd & nd & nd & $39,64,82,135,150$ \\
\hline 31 & 22.485 & Bornyl acetate & $\mathrm{C}_{12} \mathrm{H}_{20} \mathrm{O}_{2}$ & 196 & nd & 2.88 & nd & nd & nd & nd & nd & nd & 0.233 & 0.235 & $43,80,95,108,121,136$ \\
\hline 32 & 24.682 & Tetradecane & $\mathrm{C}_{14} \mathrm{H}_{3} 0$ & 198 & nd & nd & nd & nd & 0.247 & 0.227 & 0.308 & nd & nd & nd & $41,57,71,99,112,127,141,198$ \\
\hline 33 & 24.883 & r-Elemene & $\mathrm{C}_{15} \mathrm{H}_{24}$ & 204 & nd & nd & nd & 1.31 & nd & nd & nd & nd & nd & $\mathrm{Nd}$ & $41,53,68,81,93107,121,161,189$ \\
\hline 34 & 25.099 & Thymol & $\mathrm{C}_{10} \mathrm{H}_{14} \mathrm{O}$ & 150 & 0.283 & nd & nd & 1.27 & nd & nd & nd & nd & 0.275 & 0.314 & $39,65,79,91,107,135,150$ \\
\hline 35 & 25.749 & Caryophyllene & $\mathrm{C}_{15} \mathrm{H}_{24}$ & 204 & nd & nd & nd & 0.421 & nd & nd & nd & nd & nd & 0.182 & $41,67,79,91,107,135,150$ \\
\hline 36 & 26.842 & Pentadecane & $\mathrm{C}_{15} \mathrm{H}_{24}$ & 212 & 0.247 & & 0.184 & & 0.474 & 0.372 & 0.577 & & & & $41,56,85,99,127,169,212$ \\
\hline
\end{tabular}

Note: Dendranthema morifolium (Ramat.) Yellow (No.1), Dendranthema morifolium (Ramat.) Red (No.2), Dendranthema morifolium (Ramat.) Pink (No.3), Dendranthema morifolium (Ramat.) White (No.4), Pericallis hybrida Blue (No.5), Pericallis hybrida Pink (No.6), Pericallis hybrida Purple (No.7), Bellis perennis Pink (No.8), Bellis perennis Yellow (No.9), and Bellis perennis White (No.10). Nd indicates the compounds that were of too low concentration to be detected. 

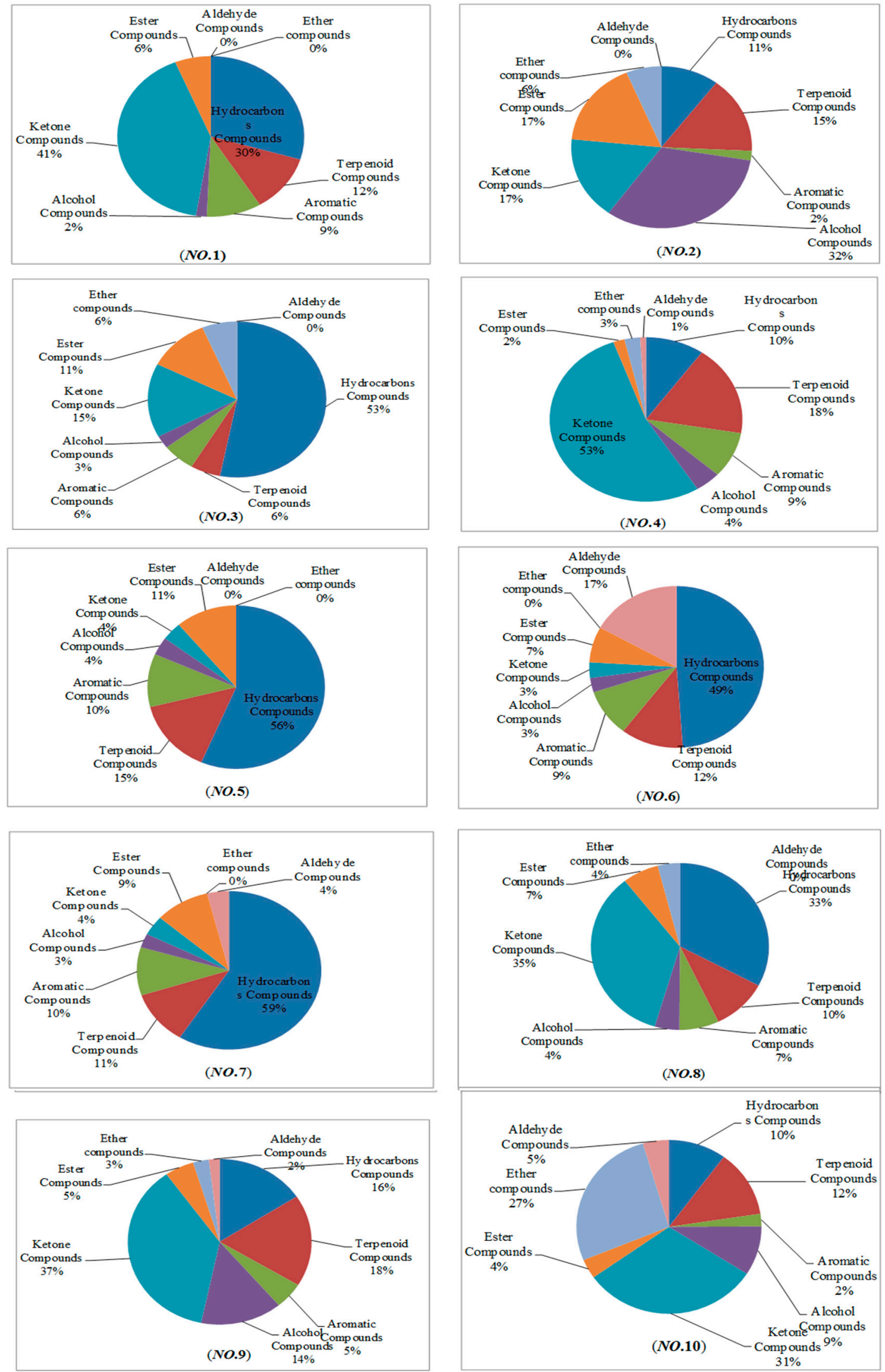

Figure 3. Percentage of terpenoids, hydrocarbons, and other compounds released from fully open Chrysanthemum samples of flowers. 


\subsection{PCA of Volatile Compounds}

The main component analysis was used to explore the data matrix order; this can help determine the weight (importance) of parameters in the total variability through vector size and loads and respective percent contributions. The PCA results give three significant principal components (eigenvalues $>1$, represents the main variables), which explain $96.509 \%$ of the variation in the data (55.802\%, 30.599\%, and $10.108 \%$, respectively).

The volatile compounds were evaluated and coded by each graded value to classify the 10 taxa of Chrysanthemum from the 3 species. Figure 4 shows the eigenvalues and their contribution through PCA using hydrocarbons, terpenoids, aromatic compounds, alcohols, ketone, ether, aldehyde, and ester volatile compounds of 10 taxa of Chrysanthemum. PCA is a method that can be used to identify patterns in a data set and to reduce dimensionality of multivariate data by removing inter-correlations among variables $[30,31]$. We obtained the eigenvalues of the matrix consisting of a component of the variance and covariance parameter. In the case of the first principal component (PC1), the eigenvalue of each of the characteristics was 5.580, thereby showing a $55.802 \%$ contribution to the total variation. The second and third PCs had eigenvalues of 3.060 and 1.011, respectively, and the degree of contribution to the total variation was $30.599 \%$ and $10.108 \%$, respectively.

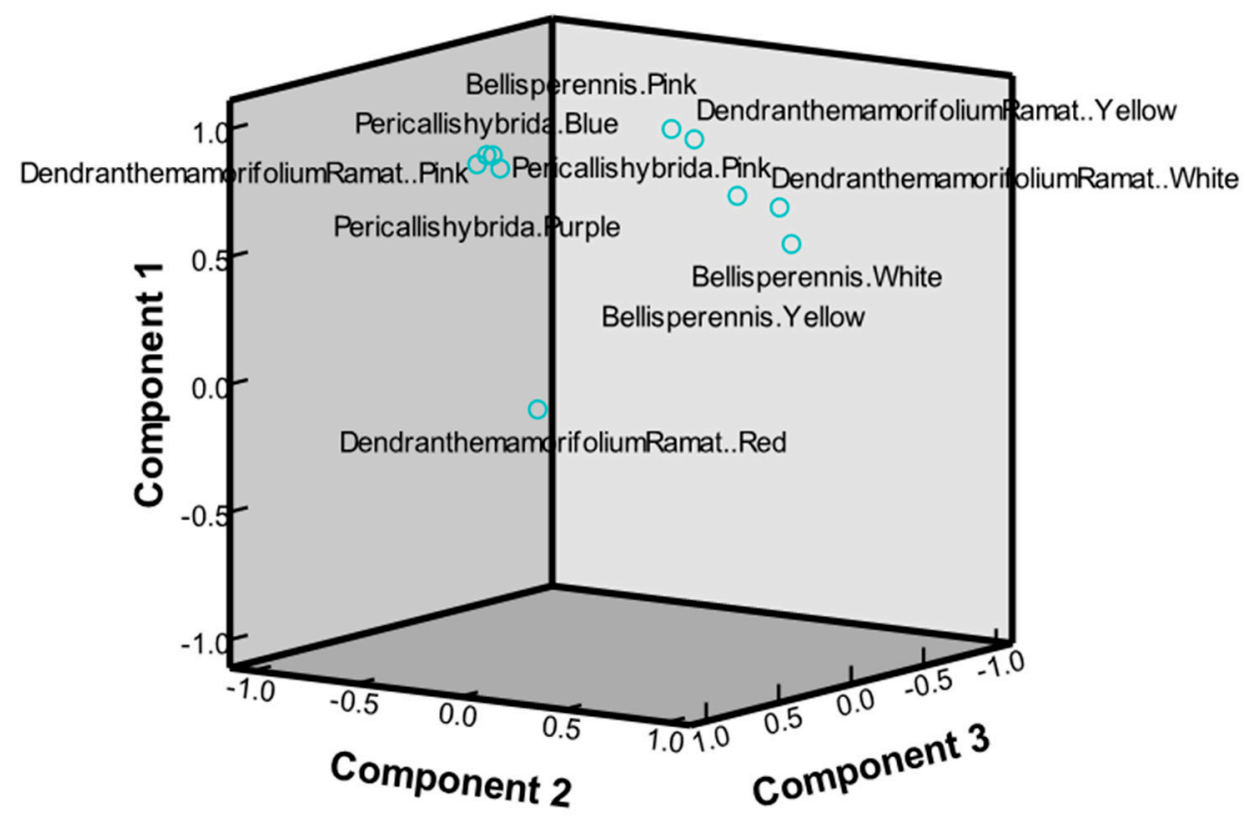

Figure 4. Eigenvalues and their contribution through the PCA using hydrocarbons, terpenoids, aromatic compounds, alcohols, ketone, ether, aldehyde, and ester volatile compounds of 10 taxa of Chrysanthemum.

In addition, to estimate the characteristics of the various volatile compounds, correlations between the individual PCs were analyzed. PC1 (55.802\% of variance) was accounted for by variables with the highest loads: hydrocarbons (1.676), terpenoids (1.535) compounds, ketones $(-0.713)$, and aldehyde compounds (-0.674). PC2, which explained $30.599 \%$ of the variation, was accounted for by the following variables: terpenoids (1.535), alcohols (0.403), and hydrocarbons (-1.736). PC3, which explained $10.108 \%$ of the variation, was accounted for by the following variables: alcohols (1.863) and aldehyde compounds $(-1.274)$. This can be interpreted as a gradient of variability among variables; positive signs mean that variables increase together, while a negative sign means that as one variable increases, the other variable decreases. It should also be noted that the sign of the terpenoids variable is the opposite of those of analysis doses because these are derived from the former (they are reciprocals). 
As a result of arranging the values of the first three PCs on a 3-dimensional scatter diagram for 10 taxa of the Chrysanthemum species, these were categorized into three groups (Figure 4): Pericallis hybrida Blue (No.5), Pericallis hybrida Pink (No.6), Pericallis hybrida Purple (No.7), and Dendranthema morifolium (Ramat.) Pink (No.3) for the first group; Dendranthema morifolium (Ramat.) White (No.4), Bellis perennis White (No.10), Bellis perennis Pink (No.8), Bellis perennis Yellow (No.9), and Dendranthema morifolium (Ramat.) Yellow (No.1) for the second group; and Dendranthema morifolium (Ramat.) Red (No.2) for the third group, respectively. In combination with the PCA, different species of chrysanthemum have differences in chemical composition.

\subsection{Cluster Analysis of Compositions of Volatile Compounds}

To compare volatile compound compositions among the 10 taxa of Chrysanthemum from 3 species, we performed a hierarchical cluster analysis based on the contents of the 36 aromatic volatile compounds. We used Ward's method for between-group linkage and the squared Euclidean distance between clusters as a proximity measurement. The 10 Chrysanthemum formed three clusters in the dendrogram (Figure 5): Pericallis hybrida Blue (No.5), Pericallis hybrida Pink (No.6), Pericallis hybrida Purple (No.7), and Dendranthema morifolium (Ramat.) Pink (No.3) for cluster I; Dendranthema morifolium (Ramat.) White (No.4), Bellis perennis White (No.10), Bellis perennis Pink (No.8), Bellis perennis Yellow (No.9), and Dendranthema morifolium (Ramat.) Yellow (No.1) for cluster II; and Dendranthema morifolium (Ramat.) Red (No.2) for Cluster III, respectively. Cluster analysis can obtain a variety of classification results according to the scale. The PCA according to the result of principal component scores got only one classification. The PCA and cluster analysis are consistent, and can classify all 10 Chrysanthemum taxa from three species.

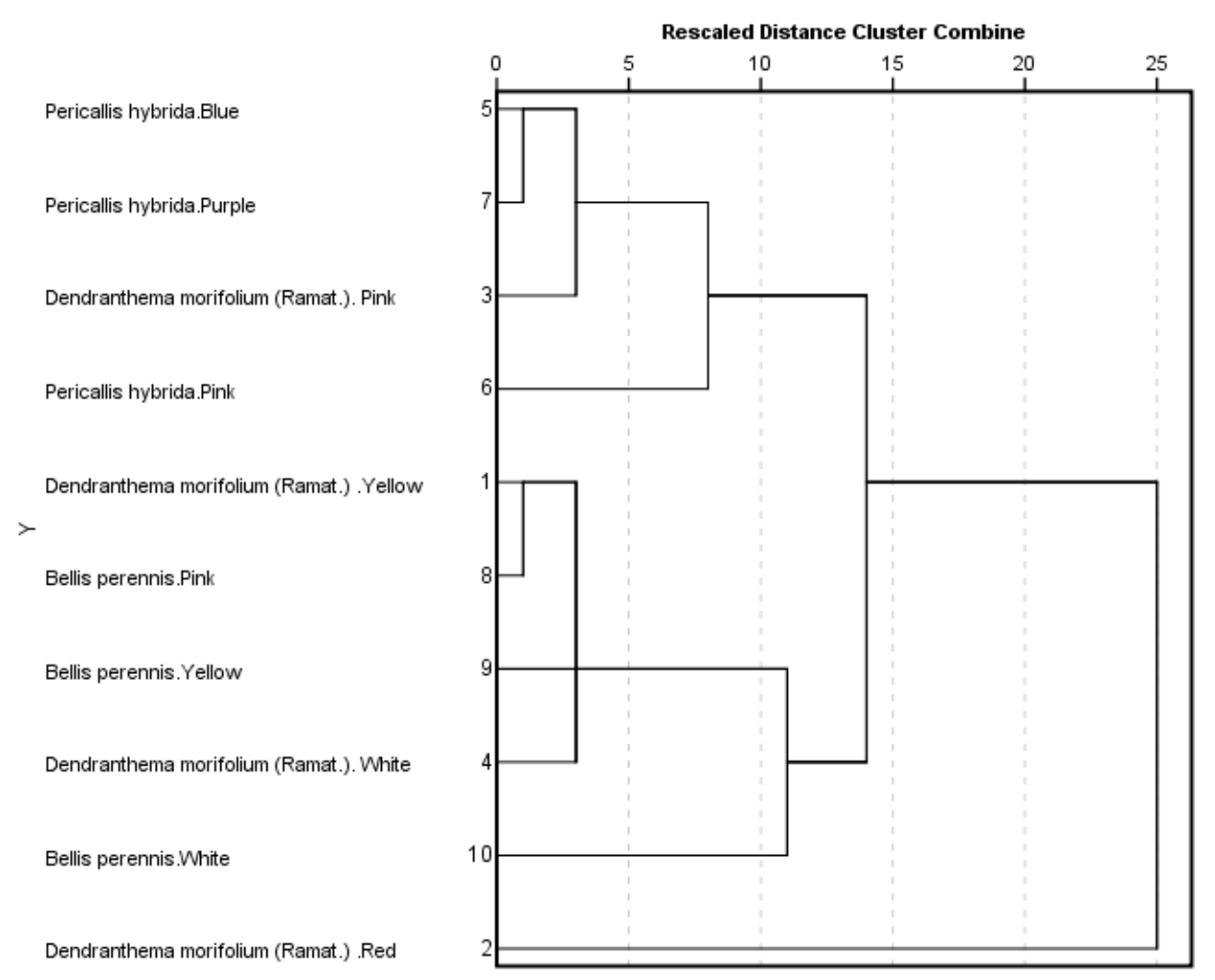

Figure 5. Dendrogram from volatile components of 10 taxa of Chrysanthemum morifolium based on Ward's minimum variance clustering method. 


\section{Discussion}

We investigated for the first time the volatile flavor compounds and antioxidant properties of essential oil that was extracted from fresh flowers, namely Dendranthema morifolium (Ramat.) Yellow, Dendranthema morifolium (Ramat.) Red, Dendranthema morifolium (Ramat.) Pink, Dendranthema morifolium (Ramat.) White, Pericallis hybrida Blue, Pericallis hybrida Pink, Pericallis hybrida Purple, Bellis perennis Pink, Bellis perennis Yellow, and Bellis perennis White. Dendranthema morifolium (Ramat.), Pericallis hybrid, and Bellis perennis. All had antioxidant activity, but our study had limitations so we were not able to further define the details of the bioactivity that is responsible for the observed effects. There were 36 volatile compounds that were identified with 8 functional groups: hydrocarbons, terpenoids, aromatics, alcohols, ketones, ethers, aldehydes, and esters. In Nos. 1, 4, 6, 8, 9, and 10, the content of camphor $(4.19 \mu \mathrm{g}, 1.29 \mu \mathrm{g}, 9.53 \mu \mathrm{g}, 2.70 \mu \mathrm{g}, 3.76 \mu \mathrm{g}$, and $4.06 \mu \mathrm{g})$ was the highest component. In No.2, the content of endo-Borneol $(6.01 \mu \mathrm{g})$ was most abundant, and it was only detected in this cultivar. In No.6, the content of the volatile compound benzaldehyde $(2.67 \mu \mathrm{g})$ was the highest component. Thus, we determined that the chemotaxonomy technique using the compositions of the volatile compounds of the Chrysanthemum species would be useful in the classification and identification of the verified inter-species differences. Finally, this study provides the basic materials needed for species selection and cultivation of Chrysanthemum species, which are useful for food, cosmetics, and medicine, further supporting the view that the flowers are promising sources of natural antioxidants. The underlying antioxidant mechanisms and potential side effects of flowers also warrant further exploration and experimentation.

\section{Materials and Methods}

\subsection{Plant Materials}

The 10 varieties of Chrysanthemum morifolium used in this study were purchased from local markets and maintained by laboratory personnel in the nursery at Xinjiang Academy of Forestry, (Urumqi, China) (Table 3). They were identified by Associate Professor Zhiyou Guo (Department of Life Sciences, Qiannan Normal University for Nationalities, Duyun, China). Alpha-Pinene standard solution (>99.9\% purity) was diluted by methanol (HPLC purity) to the concentration range of $1 \mu \mathrm{g} / \mathrm{mL}-10 \mu \mathrm{g} / \mathrm{mL}$. Then, a microliter injector (Anting micro injector factory, Shanghai, China) was used to get $0.5 \mu \mathrm{L}$ standard solution injected into Tenax TA (PerkinElmer, Boston, MA, USA); it was plugged with glass cotton in order to stop the alpha-Pinene from evaporating. Each concentration was prepared 3 times for the test.

Table 3. Dendranthema morifolium (Ramat.), Pericallis hybrida, and Bellis perennis with different colored flowers.

\begin{tabular}{cccc}
\hline NO. & Cultivar & Flower Color & Flower Diameter (cm) \\
\hline $\mathbf{1}$ & Dendranthema morifolium (Ramat.) Yellow & Yellow & 4.8 \\
$\mathbf{2}$ & Dendranthema morifolium (Ramat.) Red & Red & 4.5 \\
$\mathbf{3}$ & Dendranthema morifolium (Ramat.) Pink & Pink & 5.3 \\
$\mathbf{4}$ & Dendranthema morifolium (Ramat.) White & White & 4.5 \\
$\mathbf{5}$ & Pericallis hybrida Blue & Royal blue & 4.2 \\
$\mathbf{6}$ & Pericallis hybrida Pink & Pink & 4.2 \\
$\mathbf{7}$ & Pericallis hybrida Purple & Amaranth & 4.2 \\
$\mathbf{8}$ & Bellis perennis Pink & Pink flowers with yellow & 3.3 \\
$\mathbf{9}$ & Bellis perennis Yellow & hearts & 3.0 \\
$\mathbf{1 0}$ & Bellis perennis White & Yellow & 3.2 \\
\hline
\end{tabular}




\subsection{Extraction of Volatile Flavor Compounds}

Simultaneous steam distillation (SDE) was performed following Schultz's extraction method to extract the volatile flavor compounds [32]. Two grams of the freeze-dried leaf sample and $500 \mathrm{~mL}$ of distilled water were added to one of the flasks, and heated-reflux was performed for $2 \mathrm{~h}$ on a $100{ }^{\circ} \mathrm{C}$ heating mantle. Meanwhile, the essential oils were extracted by adding $50 \mathrm{~mL}$ of pentanediethyl ether mixture in the other flask and heated-refluxing to $40^{\circ} \mathrm{C}$. The extracted volatile flavor compounds were dehydrated using anhydrous sodium sulfate. Afterwards, they were filtered using filter paper and concentrated using 99.9\% nitrogen gas. Finally, the concentrated compounds were dissolved in $100 \mu \mathrm{L}$ of acetone, and they were analyzed using gas chromatography/mass selective detector (GC/MSD) as below.

\subsection{Sampling Collection}

A single fresh flower from Chrysanthemum morifolium was collected in a sampling bag (355 mm × $355 \mathrm{~mm}$, Reynolds, Jefferson, MO, USA). The sampling collection steps included: (a) an air sampler was used to remove the air in the sampling bag; (b) an atmosphere sampler was used to fill the air passed through the activated carbon into the sampling bag; (c) When the content of the air in the sampling bag was close to three-quarters filled, the emission volatile matter from Chrysanthemum morifolium was collected by active sampling onto the sorbent Tenax TA. Tenax-TA was chosen as it corresponds to a polymeric material (styrene polyvinylbenzene); it is commonly used as an adsorbent for semi-volatile compounds, especially for use with high temperature. The entire gas path used tasteless silicone tubing. The sampling time was fixed at 10:00-12:00 a.m. The sampling instrument volume flow rate was $100 \mathrm{~mL} \mathrm{~min}^{-1}$, with different sampling times (15, 30, and $\left.45 \mathrm{~min}\right)$. Each variety was sampled 3 times during the same testing session. Empty bags served as the control samples.

\subsection{Analytical Instrumentation}

For the ATD, a two-stage desorption was adopted to reduce the component bandwidths and improve the efficiency of the chromatographic separation. Thermal primary desorption of the sampling tubes was carried out at $250{ }^{\circ} \mathrm{C}$ with a helium flow rate of $25 \mathrm{~mL} \mathrm{~min}^{-1}$ for 20 min in order to maintain conditions strictly similar to the online sampling. The outlet split was also fixed to $5 \mathrm{~mL} \mathrm{~min}^{-1}$. The cold trap was maintained at $-30^{\circ} \mathrm{C}$. Again, during secondary desorption, the cold trap was rapidly heated from $-30^{\circ} \mathrm{C}$ to $300{ }^{\circ} \mathrm{C}$, and it was maintained at this temperature for $5 \mathrm{~min}$. Analytes were then injected onto the capillary column via a transfer line that was heated to $250{ }^{\circ} \mathrm{C}$. The outlet-split flow was adjusted for high-resolution capillary column to $10 \mathrm{~mL} / \mathrm{min}$, leading to a fraction of $50 \%$ of the sample entering the column [33].

ATD-GC-MS: automatic thermal desorption (ATD 350, PerkinElmer Corp., Norwalk, CT, USA) with gas chromatography (GC) coupled with a mass selective detector (MSD). The chromatograph was a 7890A Network GC System interfaced with a 5975C Network MSD (Agilent Technologies, Santa Clara, CA, USA), and the capillary column was a Thermo TR-5ms (60 $\mathrm{m} \times 0.25 \mathrm{~mm}$; film thickness of $0.25 \mu \mathrm{m}$ ). The MS detector provided acquisition in the full-scan mode or selected ion monitoring (SIM) mode. The ion energy of electron impact ionization was $70 \mathrm{eV}$, with the ion source temperature set to $250{ }^{\circ} \mathrm{C}$. Helium was used as the carrier gas at $1.5 \mathrm{~mL} / \mathrm{min}$ (with regulated constant flow). The GC oven was set at $40{ }^{\circ} \mathrm{C}$ for $2 \mathrm{~min}$, followed by $6{ }^{\circ} \mathrm{C} / \mathrm{min}$ to $280{ }^{\circ} \mathrm{C}$, with a final extension for $3 \mathrm{~min}$ at $280{ }^{\circ} \mathrm{C}$, and a total acquisition program of $45 \mathrm{~min}$. Mass spectral data were acquired over a mass range of 29-500 amu for the full-scan mode. The qualitative identification of targeted compounds was based on retention times. Quantification of the extracted ions was performed using the external standard method. 


\subsection{Antioxidant Capacity Analysis}

DPPH assay was performed according to the Brand-Williams method [34], which was slightly modified by Kim et al. [35]. In brief, $2 \mathrm{~mL}$ of Chrysanthemum morifolium extract solution and $2 \mathrm{~mL}$ of DPPH $(200 \mu \mathrm{mol} / \mathrm{L})$ were mixed and the absorbance was measured after $30 \mathrm{~min}$ at $517 \mathrm{~nm}$ at room temperature using an ultraviolet spectrophotometer and the effective concentration. The effective concentration (EC50) value was determined for the antioxidants. The FRAP assay was determined according to Li's method [36]. The FRAP assay measures the ability of the antioxidants in Chrysanthemum morifolium extracts to reduce the ferric tripyridyl-triazine $\left(\mathrm{Fe}^{3+}-\mathrm{TPTZ}\right)$ complex to the blue-colored ferrous form $\left(\mathrm{Fe}^{2+}\right)$, which absorbs light at $593 \mathrm{~nm}$. Briefly, a sample extract $(0.5 \mathrm{~mL})$ was mixed with $3.0 \mathrm{~mL}$ of ferric-TPTZ reagent and added to $10 \mathrm{~mL}$ PV tubes. The tubes were incubated at $37^{\circ} \mathrm{C}$ for the duration of the reaction. The absorbance was read at $593 \mathrm{~nm}$ at $75 \mathrm{~min}$ with an ultraviolet spectrophotometer (UV-2600/2700, Shimadzu, Japan).

\subsection{Statistical Analysis}

Based on the results of the GC/MSD analysis of the volatile compounds in the 10 taxa of Chrysanthemum species, ANOVA and multivariate analyses were performed using IBM's SPSS 19.0 software (IBM SPSS Institute, ver. 19.0, Chicago, IL, USA).

Acknowledgments: This work was supported by the Autonomous Region Forestry Science Foundation of Xin Jiang China (XLK, no. (2014)049, and named "The key technology of volatile composition testing and its application in the development of forestry resources"), and Forestry Industry Research Special Funds for Public Welfare Projects (201304701). We thank LetPub (www.letpub.com) for its linguistic assistance during the preparation of this manuscript.

Author Contributions: Hong Li, Jin-Hui Wang, and Lu Yang conceived and designed the experiments; Lu Yang and Nuerbiye performed the experiments and analyzed the data; Ping Cheng assisted in the completion of the experiment; Hong Li and Jin-Hui Wang contributed reagents, materials, and analysis tools; and Lu Yang and Nuerbiye wrote the paper.

Conflicts of Interest: The authors declare that they do not have any conflicts of interest.

\section{References}

1. Shinoyama, H.; Aida, R.; Ichikawa, H.; Nomura, Y.; Mochizuki, A. Genetic engineering of chrysanthemum (Chrysanthemum morifolium): Current progress and perspectives. Plant Biotechnol. J. 2012, 29, $323-337$. [CrossRef]

2. Kim, H.J.; Lee, Y.S. Identification of new dicaffeoylquinic acids from Chrysanthemum morifolium and their antioxidant activities. J. Planta Med. 2005, 71, 871-876. [CrossRef] [PubMed]

3. Ayuko, M.; Naoko, K.; Masahiro, S. Effects of a simultaneous intake of soy peptide and collagen peptide on the skin function of healthy adult women. J. Home Econ. Jpn. 2012, 63, 35-42.

4. Miyazawa, M.; Sakano, K.; Nakamura, S.; Kosaka, H. Antimutagenic activity of isoflavone from Pueraria lobata. J. Agric. Food Chem. 2001, 49, 336-341. [CrossRef] [PubMed]

5. Xia, D.Z.; Lv, G.Y.; Yu, X.F.; Wang, H.M.; Yang, Q. Antagonism of total flavonoids from Chrysanthemummorifolium against lead induced oxidative injury in mice. Zhongguo Zhong Yao Za Zhi 2008, 33, 2803-2808. [PubMed]

6. Lin, G.H.; Lin, L.; Liang, H.W.; Ma, X.; Wang, J.Y.; Wu, L.P.; Jiang, H.D.; Bruce, I.C.; Xia, Q. Antioxidant action of a Chrysanthemum morifolium extract protects rat brain against ischemia and reperfusion injury. J. Med. Food 2010, 13, 306-311. [CrossRef] [PubMed]

7. Bae, H.J.; Lee, H.Y.; Paik, J.E. Physicochemical properties of sugar-snap cookies prepared with Chrysanthemum indicum Linne powder. Korea J. Food Nutr. 2009, 22, 570-576.

8. Sung, J.Y.; Joe, W.A.; Kim, Y.H.; Cheon, S.J.; Jang, M.J.; Choi, H.J.; Lee, J.S.; Choi, E.Y.; Lee, H.S.; Kim, D.I.; et al. Study on the anti-oxidant activity of extracts from the Chrysanthemum indicum L.. J. Appl. Orient. Med. 2007, 7, 1-5.

9. Yoon, O.H.; Cho, J.S. Optimization of extractionconditions for hot water extracts from Chrysanthemum indicumL.by response surface methodology. Korea J. Food Cookery Sci. 2007, 23, 1-8. 
10. Karakas, F.P.; Şöhretoğlu, D.; Liptaj, T.; Štujber, M.; Turker, A.U.; Marák, J.; Çalış, İ.; Yalçın, F.N. Isolation of an oleanane-type saponin active from Bellis perennis through antitumor bioassay-guided procedures. Pharm. Biol. 2014, 57, 951-955. [CrossRef] [PubMed]

11. McCaffrey, C.A.; MacLachlan, J.; Brookes, B.I. Adsorbent tube evaluation for the preconcentration of volatile organic compounds in air for analysis by gas chromatography-mass spectrometry. Analyst 1994, 119, 897-902. [CrossRef]

12. Clément, M.; Arzel, S.; Le Bot, B.; Seux, R.; Millet, M. Adsorption/thermal desorption-GC/MS for the analysis of pesticides in the atmosphere. Chemosphere 2000, 40, 49-56.

13. Pankow, J.F.; Kristensen, T.J.; Isabelle, L.M. Effects of flow rate and temperature on the thermal desorbability of polycyclic aromatic hydrocarbons and pesticides from Tenax-GC. Anal. Chem. 1983, 55, 2187-2192. [CrossRef]

14. Esteban, J.L.; Martinez-Castro, I.; Morales, R.; Fabrelles, B.; Sanz, J. Rapid identification of volatile compounds in Aromantic Plants by automatic thermal desorption-GC-MS. Chromatography 1996, 43, 63-72. [CrossRef]

15. Zhang, Y.; Lin, W.K.; Zheng, H.; Li, K. Analysis of Volatiles from Jacaranda mimosifolia D. Don by ATD-GC/MS and Evaluation for Its Horticultural Fragrance. J. Anhui Agric. Sci. 2013, 41, 4450-4451.

16. Coldwell, M.R.; Pengelly, I.; Rimmer, D.A. Determination of dithiocarbamate pesticides in occupational hygiene sampling devices using the isooctane method and comparison with an automatic thermal desorption (ATD) method. J. Chromatogr. A 2003, 984, 81-88. [CrossRef]

17. Sung, W.H. Principal Component Analysis Applied Multivariate Statistics, 2nd ed.; Tamjin Press: Seoul, Korea, 2000.

18. Kim, S.J.; Lee, C.H.; Kim, J.; Kim, K.S. Phylogenetic analysis of Koreannative Chrysanthemum species based on morphological characteristics. Sci. Horticult. 2014, 175, 278-289. [CrossRef]

19. Chung, K.H. Morphological characteristics and principal componentanalysis of plums. Korea J. Hort. Sci. Technol. 1999, 17, 23-28.

20. Yun, J.S.; Son, S.Y.; Kim, I.H.; Hong, E.Y.; Yun, T. Classification of Polygonatum ssp. collections based on multivariate analysis. Korean J. Med. Crop. Sci. 2002, 10, 333-339.

21. Davis, J.C. Statistics and Data Analysis in Geology; John Wiley \& Sons: Singapore, 2002; pp. 517-638.

22. Harris, R.J. Primer of Multivariate Statistics, 2nd ed.; Academic Press: Tallahassee, FL, USA, 1985; pp. 576-577.

23. Halliwell, B. Free radicals, antioxidants, and human disease: Curiosity, cause, or consequence? Lancet 1994, 344, 721-724. [CrossRef]

24. Finkel, T.; Holbrook, N.J. Oxidants, oxidative stress and the biology of ageing. Nature 2000, 408, $239-247$. [CrossRef] [PubMed]

25. Sardy, M. Role of matrix metalloproteinases in skin ageing. Connect. Tissue Res. 2009, 50, 132-138. [CrossRef] [PubMed]

26. Wlaschek, M.; Briviba, K.; Stricklin, G.P.; Sies, H.; Scharffetter-Kochanek, K. Singlet oxygenmay mediate the ultraviolet A-induced synthesis of interstitial collagenase. J. Investig. Dermatol. 1995, 104, 194-198. [CrossRef] [PubMed]

27. Raeppel, C.; Nief, M.; Fabritius, M.; Racault, L.; Appenzeller, B.M.R.; Millet, M. Simultaneous analysis of pesticides from different chemical classes by using a derivatisation step and gas chromatography-mass spectrometry. J. Chromatogr. 2011, A1218, 8123-8129. [CrossRef] [PubMed]

28. Figuieredo, A.C.; Barroso, J.G.; Pedro, L.G.; Scheffer, J.J.C. Factors affecting secondary metabolite production in plants: Volatile components and essential oils. Flavour Fragr. J. 2008, 23, 213-226. [CrossRef]

29. Iezzoni, A.F.; Pritts, M.P. Applications of principal component analysis to horticultural research. Horticult. Sci. 1991, 26, 334-338.

30. Zhu, S.; Yang, Y.; Yu, H.; Ying, Y.; Zou, G. Chemical composition and antimicrobial activity of the essential oils of Chrysanthemum indicum. J. Ethnopharm. 2005, 96, 151-158.

31. Emerit, I. Free radicals and aging of the skin. EXS 1992, 62, 328-341. [PubMed]

32. Schultz, T.H.; Flath, R.A.; Mon, T.R.; Eggling, S.B.; Teranishi, R. Isolation of volatile compounds from a model system. J. Agric. Food Chem. 1977, 25, 446-449. [CrossRef]

33. Briand, O.; Millet, M.; Bertrand, F.; Clément, M.; Seux, R. Assessing the transfer of pesticides to the atmosphere during and after application.Development of a multiresidue method using adsorption on Tenaxand thermal desorption-GC/MS. Anal. Bioanal. Chem. 2002, 374, 848-857. [CrossRef] [PubMed] 
34. Brand-Williams, W.; Cuvelier, M.E.; Berset, C. Use of a free radical method to evaluate antioxidant activity. LWT-Food Sci. Technol. 1995, 8, 25-30. [CrossRef]

35. Kim, D.O.; Lee, H.J.; Lee, C.Y. Vitamin Cequivalent antioxidant capacity (VCEAC) of phenolic phytochemicals. J. Agric. Food Chem. 2002, 50, 3713-3717. [CrossRef] [PubMed]

36. Li, H.Y.; Deng, Z.Y.; Zhu, H.H.; Hu, C.L.; Liu, R.H.; Christoper, J.Y.; Rong, T. Highly pigmented vegetables: Anthocyanin compositions and their role in antioxidant activities. Food Res. Int. 2012, 46, 250-259. [CrossRef]

Sample Availability: Samples were purchased from local markets (Urumqi, China).

(C) 2017 by the authors. Licensee MDPI, Basel, Switzerland. This article is an open access article distributed under the terms and conditions of the Creative Commons Attribution (CC BY) license (http://creativecommons.org/licenses/by/4.0/). 